\title{
Analysis of Educational Quality, a Goal of Education for All Policy
}

\author{
Dr. Rehaf A. Madani ${ }^{1}$ \\ ${ }^{1}$ Lecturer at the American University in Dubai AUD, Dubai, United Emirates \\ Correspondence: Lecturer at the American University in Dubai AUD, Dubai, United Emirates. E-mail: \\ rehafmadani@hotmail.com
}

Received: November 15, 2018

Accepted: December 7, 2018

Online Published: January 17, 2019

doi:10.5539/hes.v9n1p100

URL: https://doi.org/10.5539/hes.v9n1p100

\begin{abstract}
Education is recognized as a human right since the adoption of Universal Declaration of Human Rights in 1948 besides health and shelter. Education for All Goals was established where more than 150 governments have adopted world declaration on Education for All policy to support the universal right for education. The ultimate goal of many countries is to guarantee the optimum educational access rates for improving the quality. Similarly, quality is reflected by a range of indicators, including government spending on education, student/teacher ratios, teacher qualifications, test scores, and the length of time students spend in school. Every investment must be measured against how it can serve such aspects to ensure the ultimate quality of Education for All programs. Investing in education reinforces a society's wealth and growth, where individuals can easily improve their own personal efficacy, productivity, and incomes. A major challenge lies in defining the ideal education indicators and circumstances among countries; especially poorly developed countries that strive to establish a quality evaluation theme. Therefore, there is need of multifaceted standpoint and reasoning framework to realize educational policy evaluations that can truly contribute to the improvement of educational situation in developing countries and around the world.
\end{abstract}

Keywords: education, policy, qualification, quality education access, teacher

\section{Introduction}

Education is an essential tool for social and economic growth of a country. The basic educational skills; like reading and writing increases a person's income up to $10 \%$ acting as the perfect weapon that lifts individuals to freedom, which helps to eradicate international poverty and hunger. Different nations of the world have declared that it is the right of every person to get education by speaking through the Universal Declaration of Human Rights (World education forum, 2000). Since then, numerous organizations have struggled to promote education through the implementation of new educational strategies and policies. These organizations include; United Nations Educational, Scientific, and Cultural Organization (UNESCO), Convention against Discrimination in Education (1960), the International Covenant on Economic, Social and Cultural Rights (1966) and the Convention on the Elimination of All Forms of Discrimination against Women (1981) (UNICEF, 2007).

Education for All policy (EFA) has been launched at World Conference in 1990 that as a universal commitment that provides quality basic education for all children, youth, and adults. Education for All Goals were established at Jomtien (Thailand) in 1990, where more than 150 governments adopted world declaration on Education for All policy and committed to support the universal right for education by achieving free quality education access. It was reaffirmed 10 years later in 2000 World Education Forum in Dakar (Senegal), where following six Education for All goals were adopted to be implemented by 2015;

- First goal is to expand and improve early childhood care and education;

- Second is to achieve gender parity by 2005 and equality by 2015 ;

- Third is access to free, quality, and compulsory primary education to all;

- Fourth is to increase adult literacy by $50 \%$;

- Fifth is to promote learning and life skills improvement for youth and adults;

- Finally, to improve every aspect of educational quality.

Quality of education is considered to be the heart of Education for All (UNESCO, 2000a). Babalola (2004) stated 
that quality of education refers to the worth of education (with reference to its input, the teaching- learning process and the output/outcome). The Jomtien Declaration in 1990; and more particularly, Dakar Framework for Action in 2000 recognized that Education for All policy cannot be achieved without the improvement of its quality. Most of the goals; such as the enhancement of early childhood education, improvement of adult literacy, and life-skills programs, are affected by the quality of educational contents and the quality of educators themselves. Governments around the word have greatly participated in their citizens' education. Huge amounts of resources are invested in education annually for the sake of improving the learning process. However, the standard and quality of education does not meet its potential in most of the cases especially in the developing counties. Haddad and Demsky (1995) stated that education policy-planning process: an applied framework" and World Bank Logical Framework Handbook (2005) aims to analyze "Education of All policy: The Quality Imperative of the EFA Global Monitoring Report". This approach is likely to provide a comprehensive empirical analysis of the educational quality.

\section{Literature Review}

\subsection{Policy Definition and Scope}

Educational policy is considered as a program related to the design of Education for All program, concentrating on specific area of its quality (Haddad \& Demsky, 2005). Quality of education is a broad concept and there is no single definition that has identified the exact meaning of quality due to its complex nature. Terms; like effectiveness, equity, efficiency, and quality have often been used synonymously (Adams, 1993). The definition of quality should always be flexible for change to cope with educational evolution and its continuous progress (Glasser, 1990) as quality is influenced by various changing factors; such as, politics, culture, and economy. EFA Global Monitoring Report (2005) used two principles to define the educational quality:

- The first is to recognize the cognitive development of learner's as the major objective of all education systems.

- The second is to highlight the role of education in promoting the values and attitudes of the learners and in nurturing their creative and emotional development.

\subsubsection{Goal}

The main focus of 2005 Quality Imperative report is related to the improvement of educational quality and the progress towards achieving the Millennium Development Goals (MDGs) to overcome extreme poverty. It is helpful to decrease the spread of HIV/AIDS and to provide universal primary education. Quality of education is aimed to enhance all features of educational quality by ensuring excellence in all educational progresses, inputs, and outputs especially in literacy, numeracy, and essential life skills.

\subsection{Analysis of the Existing Situation}

A policy change, as described by Haddad \& Demsky (1995), is usually a response to a problem or a malfunction in a sector. In this case; focusing on the quality of education is essential to achieve the ultimate goal of Education for All. In addition to the analysis of Education for All, policy analysis should review several aspects that has affected the decision-making and implementation process of the educational sector.

Quality education includes: learners, learning environments, content, process, and outcomes. EFA Global Monitoring Report (2005) has adopted a framework, comprised of such five major factors, which has affected the quality of education and influence its core process of teaching and learning. This has provided a better understanding of educational complex system. These dimensions are interdependent and influencing each other in unpredicted ways. Focusing on their interactions can help to draw up a comprehensive map for understanding, monitoring, and improving the quality of education.

\subsection{Quality Learners}

The learners are considered as the core, while setting an educational policy with the attempt to ensure its quality. Thus, it is said that "The quality of learning is and must be at the heart of EFA" (UNESCO, 2000). It is said that knowledge, interests, capacities. and circumstances (gender, race, culture, language, religion, social status and migration) should be taken into consideration, when setting certain strategies to improve educational quality factors among students.

\subsubsection{Good Health and Nutrition}

Physical and psychosocial health always affect the students' cognitive developments and academic performance, especially in their early childhood lives (McCain \& Mustard, 1999). 


\subsubsection{Family Support for Learning}

Parents' background and level of education plays an important role in students' educational quality. Financially, parent's income and social status highly affect the decision of children enrolment in schools, especially in developing countries (Carron \& Chau, 1996). Academically, Williams (2000) revealed that children with poor educated parents have achieved three times lower scores or grade repetition as compared to those with parents with some secondary schooling. Successful attempts to enhance parental involvement especially in developing countries need to be considered. In Sri Lanka, an eight-week program was conducted to enhance literacy skills of uneducated low-income mothers that has a positive effect on their children's educational outcomes (Dharmadasa, 1996).

\subsubsection{Regular Attendance for Learning}

It is said that regular school attendance and constant exposure to curriculum influence students' achievement levels (Fuller et al., 1999). As consistent with many research findings, a village-based study that took place in Malawi confirmed that students with higher attendance rates have attained higher learning achievements (Miske \& Dowd, 1998).

\subsubsection{Early Childhood Psychosocial Development Experiences}

Early childhood exposure to experience and interactions positively affect their cognitive and psychosocial developments. Willms (2000) has demonstrated that a child's attendance to daycare, accompanied with higher levels of parental involvement is associated with higher performance in primarily schools.

\subsection{Quality Learning Environments}

Quality learning environments highly influence the quality of learning, and are made up of physical, psychosocial, and service delivery elements.

\subsubsection{Class Size}

Developing countries have witnessed a massive increase in students' access and enrollment to primary education, which is considered as an achievement of EFA goal. It resulted in class size expansion to accommodate as much students as possible. UNICEF/UNESCO survey, conducted in 1995, stated that class sizes have ranged from around 30 students in rural and urban Bhutan, Madagascar, and the Maldives, 73 in rural Nepal, and 118 in Equatorial Guinea (Postlewaithe, 1998). Even though; some studies have detected a relation between class size and students learning outcomes; however, results were not consistent (Rutter, 1979).

\subsubsection{Quality of School Facilities}

The quality of school facilities has an indirect impact on learning outcomes. In Latin America; a study recruited 50,000 students from grades three and four. The results indicated that repetition rates and achievement levels of students with poor classroom equipment and school facilities were much lower as compared to those who belonged to well-equipped schools (Willms, 2000).

\subsubsection{Peaceful, Safe Environments, Especially for Girls}

A non-discriminatory climate within schools and classrooms is critical, when creating a quality-learning environment. Gender and race equality along with other efforts have improved the learning environment for girls and all students leading to actual results (Sutton, 1999).

\subsubsection{Interaction between School Infrastructure and other Quality Dimensions}

The location and conditions of schools regarding building's quality including the maintenance and availability of basic equipment; such as, furniture, textbooks, lavatory, and clean water supply. Here, the students did not have to leave the premises for their primary needs that has an impact on the quality of teaching and learning process and students' participation.

\subsubsection{Inclusive Environments}

Reduction of all types of discrimination; such as, gender, ethnic, social, and economical discrimination, is critical for the enhancement of educational quality. Significant gaps are found between inclusive policies for students with disabilities or special needs (Mitchell, 1995). Continuous restructuring of educational environment is required to improve the learning of all children regardless of their abilities or backgrounds.

\subsubsection{Teachers' Behaviors that Affect Safety}

Teachers' behaviors have a massive effect on learning environments and student participation. Learning cannot take place, when the basic needs of survival and self-protection are threatened as the case in Ethiopia. There was 
increase in students' withdrawal rates due to fear of teacher harassment, violence, and lack of discipline (Verwimp, 1999).

\subsubsection{Service Delivery}

The primary cause of student absenteeism from school is illness (Carron \& Chau, 1996). Improvements of school-based health programs, addressing issues of health, and nutrition have been implied to decrease students' cognitive functions. It has resulted in positive effects that has contributed to quality school environments (Dolan, Drake, Maier, Brooker \& Jukes, 2000).

\subsubsection{Effective School Discipline Policies}

Setting classroom rules and school policies that have been agreed among students, teachers, and administers is necessary to achieve order, discipline, and reinforcement of overall positive behaviors (Craig, Kraft \& du Plessis, 1998).

\subsection{Quality Content}

\subsubsection{Life Skills}

UNICEF defined life skills as psycho-social and interpersonal skills used in every day interactions...not specific to getting a job or earning an income (UNICEF, 2000). Life skills curriculum mainly focuses on students' attitudes, behavioral change, and values. Moreover, it is incorporated within the teaching system in different ways. In Rwanda, it is taught as a part of cooperation and communication along with conflict resolution and self-awareness. However; it is incorporated through HIV/AIDS informative courses in Zimbabwe (UNICEF, 2000).

\subsubsection{Student-centered, Non-discriminatory, Standards-based Curriculum Structures}

Several points are considered for structuring a curriculum that mainly include deep coverage of important areas of knowledge and individual differences. Moreover, the structure should be gender sensitive and inclusive of children with different abilities and backgrounds, responsive to arising issues as HIV/AIDS and conflict resolution, grade level appropriate, properly sequenced, and clearly defines learning outcomes (Glatthorn \& Jailall, 2000)

\subsubsection{Literacy}

One of the main goals of education is to master literacy skill, which is the basic ability to read and write.

\subsubsection{Numeracy}

Numeracy covers a wider range of skill sets from basic arithmetic and logical reasoning to advanced mathematics and interpretative communication skills (Steen, 1999). It is also known as "quantitative literacy"; and is incorporated in most subjects of the curriculum, including science, geography, and social studies. Moreover, it further improves participation in life tasks like making sense of financial situations and effective community and nation contribution.

\subsubsection{Uniqueness of Local and National Content}

It is said that the local and national values of every region are usually incorporated within its curriculum. The content includes central subjects; such as, math, science, life skills, literacy, and social studies that are usually standardized. These subjects share minimum variations to assure high quality equal education.

\subsubsection{Challenges in Reaching Large Numbers of Children with Quality Content}

Educators seeking to improve the quality of education by expanding successful programs beyond the assigned ones usually face certain difficulties and retention regardless of its success and available resources. Obanya (1995) justified the reason behind the rejection of curricular integration; social attitudes toward the subject; cultural patterns that are difficult to change; political and economic instability; and teacher/student turnover.

\subsection{Quality Processes}

Recently educational process and the inputs of teachers and administrators have gained special attention to ensure quality educational process.

\subsubsection{Teacher Competence and School Efficiency}

The quality of a school and the quality of teaching of the individual teacher is higher in schools that are able (and willing) to make more efficient use of the available time of its teachers and its pupils (Verwimp, 1999). Teachers' presence in the classroom also improves the quality of education. Moreover, teachers face different types of 
obstacles in underdeveloped countries that lead to their absence; such as, transportation and housing problems or juggling between two jobs. Studies from India, Indonesia, Ghana, Nigeria, Zambia, and Lebanon have shown that teachers are absent for $25-30 \%$ of the time or work for fewer hours. During the teacher's absence the students are either left alone or attended to by other teachers, who were asked to compensate for absent ones (Abadzi, 2004).

\subsubsection{Teacher Feedback Mechanisms}

A good teacher is the key to educational quality and reformation. Skilled teachers are those, who not only master instructional methods; but are also capable of evaluation and assessment practices. Unfortunately, majority of the teachers in developing countries rely exclusively on traditional teaching techniques that depend on the memorization route rather than cognitive skills (Colby, 2000).

\subsubsection{Professional Learning for Teachers}

Students' educational achievement is directly influenced by teachers' command especially in early primary years. Therefore, quality of the teacher is always associated with quality of education. Teachers' qualifications in terms of the achieved educational levels, efficiency, and training vary significantly across the globe that results in verifying quality of education.

\subsubsection{Continuing Support for Student-centered Learning}

Traditional teaching styles should be reformed to ensure quality education, which would lead to the improvements of students' attitudes, beliefs, cognitive skills, and expansion of their knowledge level.

\subsubsection{Ongoing Professional Development}

Professional development and ongoing teacher's training programs have positive direct impact on students' achievable levels. Moreover, teachers should depend on dialogue and reflections with colleagues, journals, and peers' and supervisors' observation to increase their knowledge (UNICEF, 2000). Mombasa school improvement project in Kenya revealed that teachers attending in-service and external workshop training showed improvements in their ability to use student centered teaching and learning techniques (Anderson, 2000).

\subsubsection{Teacher Beliefs that all Students can Learn}

Students' achievements should be the school's first priority to ensure educational quality. Low expectations of students' performance penetrate educational systems in many developing countries rather than setting high standards which students are encouraged to meet.

\section{Methodology}

The study has aimed to analyze the educational quality based on the goal of education for all policy. A brief literature review was conducted for identifying the studies that are associated with analysis of educational quality. The tie period selected for this study was between 1990 and 2010. The study has been divided into following sub-themes that include; analysis of supervision and support, evaluation of study policies, and outcomes.

\section{Analyzing the Supervision and Support}

\subsection{Student Access to Languages Used at School}

Language policy implementation faces various debates on which language to incorporate in the early years of primary education. Much discussion is focused on whether the mother language of the country or a foreign language (English or French) should be instilled in the early learning years. Many parents and teachers encourage the focus on foreign language claiming that learning in the mother tongue can compromise students learning French or English later. Some even believed that their mother language is not capable to deal with scientific and technical concepts. Therefore, it results in a linguistic gap among students that is usually overlooked (Cazden, 2000). Other research has proven that students using the mother langue in school have improved reading abilities by the end of grade one as compared to the students in less developed countries dealing with linguistic complexes (Abadzi, 2004).

\subsection{Using Technologies to Decrease Rather than Increase Disparities}

Technology is used globally for increasing the quality of education and overcome the gaps of students' inequality. Despite all of this technology; learning tackles a part of the educational process while the human factor still remains the most effective factor in education.

\subsection{Administrative Support and Leadership}

Quality of administrative support and leadership is an essential element in teaching and learning processes. 
Government and organizational support can take many forms to support the educational system by ensuring sufficient financial resources, fighting for better schools and learning conditions and encouraging personal development has shown a positive effect on students learning.

\section{Results}

The present study has illustrated that there is a critical relationship between students' educational outcomes and quality of environment, content, and process of the educational journey the learners experienced, as the journey is diverse.

\subsection{Outcomes Related to Community Participation, Learner Confidence and Life-long Learning}

Academic achievements usually indicate school's quality; while other outcomes like citizenship education and skills for behavioral developments are more complex to measure. DeKetele (2000) distinguished four levels of citizenship education outcomes

- Students knowledge of their human rights

- The ability to analyze social situations related to citizenship values

- The ability to use participative pedagogy and work cooperatively within a group

- Taking responsibility of their community as in management and decision-making situations

\subsection{Using Formative Assessment to Improve Achievement Outcomes}

Annual assessment of students' academic performances and outcomes are significantly important. It helps teachers to assess and determine alternative teaching strategies that are recommended for improving educational quality for individuals and systems.

\subsection{Achievement in Literacy and Numeracy}

Students' academic achievements in terms of reading, writing, and numeracy skills are considered as the primary purpose of education. In the past years, various researches have been conducted to analyze the relationship between students' level of literacy and numeracy skills with regards to the years of schooling. Studies revealed that students achieved lower levels of literacy in low-income countries, when compared with students from high-income countries with a similar amount of schooling (Willms, 2000).

\subsection{Outcomes Sought by Parents}

Possible future employment is the primary reason for parents to educate their children in majority of the developing countries. Parents tend to assign more importance to educational outcomes as a measure of school quality than students, teachers or principals.

\subsection{Health Outcomes}

General literacy and socialization provided by schools have been shown in particular to affect women's maternal behavior and reproductive health (LeVine, 2000). Educational quality has proved to have a direct positive impact on students' health related issues. Some schools offer students services to improve their health; such as treatment for illness and infection, another factor is the school's feeding program is to improve nutrition. Moreover, the curricular content to enhance students' knowledge regarding health and hygiene related behaviors.

\subsection{Experiential Approaches to Achieving Desired Outcomes}

Schools carry a massive effect on building students' social capital and encouraging community participation and responsibility along with promoting quality affective behavioral outcomes for children. It usually happens within the schools' premises; but some programs have discovered experiential community-based approaches that can help to aid these positive behavioral outcomes.

\subsection{Life Skills and Outcomes}

It is important to incorporate psychosocial and interpersonal skills within the context of assigned curricula topics; like HIV/AIDS prevention, drug abuse prevention, nutrition, and hygiene behavior. Moreover, many non-health contexts are important to help students grow their daily evaluative and behavioral skills.

\section{Discussion}

There is a wide potential to increase the quality of teaching and learning in every country, school, and classroom. Significant improvements in the quality of education are not impossible by referring back and analyzing rich body of circumstances and experiences. Policies must be inclusive and respond to the diverse backgrounds, needs, and circumstances of all learners. Priorities to low-income countries with severe resource constraints should be considered by focusing on defining the appropriate goals and relevant contents. Educational policies 
should not be beyond the reach of such countries to facilitate implementation and achievement of desired outcomes.

EFA Global Monitoring Report (2005) Education for All pointed out key policy options to improve the educational process focusing on low-income developing countries. Areas to be addressed focusing on school effectiveness include:

- Investment in policies regarding teachers' recruitment, salaries, and conditions of service; reformation of teacher training and school management to imply culture related teaching/learning methods by addressing pedagogically sound language policy; and giving children the authorization to use their mother language for the first years of school.

- Teaching and learning policy decisions must focus on establishing suitable curriculum goals, development of relevant content, instructional time management, ensuring effective pedagogy, attentive consideration while selecting the appropriate language of instruction and the development of sound assessment policy, learning material supply, and distribution and securing a physical environment with sufficient facilities.

- To enhance the establishment of partnerships among different parts of education sectors for improving the quality of education and terminate corruption

- Accessibility of quality learning materials, for local publishers.

- Encouragement of self- government schools that are managed by well-defined liability frameworks reliable leadership.

- Acknowledgement of the diversity of learners as that of special educational needs and the implementation of useful educational approaches for the disadvantaged groups

- Better schools, policies concerning self- government schools and improvement of leadership.

- Aid resource-constrained schools in making use of their limited resources by investing in services, networks and structure designs to help share local contextual education knowledge (UNESCO-Santiago, 2003).

\subsection{Evaluation of Policy Options}

Education reform policies are more likely to achieve their goals if they are fair to all legitimate stakeholders, respect schools' organizational integrity, link ends and means realistically, are consistent with other state actions, are cost effective, and are politically achievable (Mitchel, 1986). Educational reforms are usually made to improve the educational system situation in terms of access, equity, quality, relevance, efficiency, and cost/finance (Williams and Cummings, 2005). Developing countries are confronted with serious problems in all of these aspects by identifying priority issues and translating them into policies in actual educational settings. Evaluation is defined as a set of activities in which the segments of educational system aim to fulfill six conceptual goals each with its own analysis and multiple objectives is a heroic task (Arturo \& Estrada, 2011). There is an urgent need to develop a coherent and wholesome evaluation and monitoring system.

\subsection{Existence of Evaluation System}

Until now, no exact method has been developed to monitor or measure the quality of the educational system. The nonexistence of evaluation surveys is mainly limited to traditional forms with an unclear standard or a common criterion. Therefore, a comparison cannot be made between the assigned grades and the results of evaluation surveys.

\subsubsection{Existence of Educational Standards as a Reference Point}

A noticeable gap arises between educational program designs and its implementation among different cultures. Therefore, educational standards cannot be generalized especially in the rural countries, where standard requirements are not fulfilled. Standards vary according to the conditions of schools, teachers, management, available resources, and learning and teaching process. Without fixed standards evaluators will find difficulties to identify what needs monitoring and to what degree of achievement it should be measured.

\subsubsection{Acceptance of the Educational Standards}

Actors involved in the system should accept the importance of educational standards. The implementation and monitoring of quality must be encouraged to achieve desirable results. For example, most of the parents disregard the importance of formal schooling in most undeveloped countries as they are more focused on teaching the skills vital for agricultural work. 


\subsubsection{Equity in the System of Monitoring and Evaluation}

The universality of 'pilot study cultures' that are used as a base for comparison, evaluation, and implementation of new educational policies usually concerns a certain local level, which cannot be generalizable for the national educational system with minimum funding. Equity in providing the necessary conditions internationally among schools is vital to ensure fairness of the evaluation, where quality is a mirror reflection of equity.

\subsubsection{Lack of Sufficient Data and Qualitative Research}

This report has used to assess any educational policy that is dependent on quantitative data. However, quantitative results cannot reveal outcomes related to quality and efficiency of provided educational programs. Therefore, it is proven by the recognizable gap between the number of graduating students from schools and the number of those students, who master the basic set of cognitive skills. Moreover, the vast expansion of new primary schools makes evaluation and assessment an impossible task, which seems to be detrimental to quality.

\subsubsection{Financial Resources}

The objective of improving educational quality is often overlooked; however, the required budget identifies the effective cost for quality improvement. Abadzi (2004) mentioned that the actual cost of 'Education for All goal' might reach four to five times the estimated budget to provide basic literacy skills. Therefore, more effort is required to ensure that the available aid is used and it is directed towards countries that need it the most. Another factor is the irrelevance of working staff, which are usually hired for their financial ability, strategic, and project management experiences. Therefore, World Bank has declared in 1990s that only 20-25\% of the working manpower in the sector had any degrees in education (Heyneman, 2003).

\section{Conclusion}

Educational policies cannot be treated as one size fits all endeavors due to different educational conditions and surroundings of each country. Policies; especially the Education for All, should be flexible for utilizing the need of each country's political, economic, social, and cultural situations and backgrounds. It has been evaluated that quality is reflected by a range of indicators, including government spending on education, student/teacher ratios, teacher qualifications, test scores, and the length of time students spend in school. Every investment in basic education must be measured against how well it serves these different aspects to ensure the ultimate quality of the Education for All programs. The ultimate goal of most countries is to guarantee the optimum educational access rates of their children, overlooking the core issue of education, which is quality. Investing in education reinforces a society's wealth and growth, where individuals can improve their own personal efficacy, productivity, and incomes. A major challenge lies in defining the ideal education indicators and circumstances among countries; especially poorly developed ones to establish a quality evaluation theme. A multifaceted standpoint and reasoning framework should be established to realize educational policy evaluations that contributes towards the improvement of educational situation in developing countries and around the world. The scope for improving the quality of education is vast and the requirement of technical understanding has all been researched. Therefore, the future studies are required to identify more comprehensive outcomes.

\section{Recommendations and Implications}

It is almost impossible to implement the educational policies internationally using the same set of standards, especially among low-income countries due to the broad spectrum of educational quality. Assessment and evaluation of quality system has been effective within a country or school where it is possible to control learning conditions, standards, and relative points. Educators around the world have been using different approaches to achieve school quality improvement; however, it is difficult to achieve a united set of standards and conditions. The four significant components focused by the educational program include;

- Concentrated on the improvement of learning environment, including infrastructure, provision of classroom libraries, and learning materials

- Focused on the critical matter of teacher and supervisor training programs through weekly workshops that took place within the schools' premises. They focused on quality instructional practices to facilitate change in teachers' knowledge, skills and attitudes to improve the overall teaching methods and the ability to work more effectively with the local culture and community.

- Focused on strengthening learning and improving self-esteem and social competence on assisting lower-achieving students through workshops that were delivered by trained community members.

- Provision of new developed textbooks for every student, while teachers on the other hand, received training on the new materials as part of their weekly workshops along with manual transcripts for references and guidance. 
It has been indicated that the progress of Education for All is increasing internationally; but serious and persistent problems remain in improving the quality of basic education especially among rural countries. Aid providers are becoming intimidated by higher cost and difficulty of achieving EFA seeking for more promising achievable sectors. The present study has recommended greater attention on the relevance of external support and capacities for more cutlery suitable educational solutions within the frame of Educational for All global goals. Investments are required in teachers' developing programs; especially in resource restricted countries to address the gaps in teacher quality. Investments are also needed in materials and human resources to expand and update the monitoring and evaluation systems. It has been shown that there is need to develop teachers' capabilities for different school levels, which could be a framework used for further reform efforts to improve teacher education. Quantitative aspects should be the main focus of attention for educational policy makers; therefore, more qualitative research is required to understand and identify the areas that need local planning and evaluation. Narrowing of Education for All funding to countries with cooperative governments is required to ensure educational progress implementation. Moreover, the correlation between educational organizations, aid providers, and government of each region is needed to discuss and plan findings that can contribute to the enhancement of quality of education aspects.

\section{Acknowledgements}

The author is very thankful to all the associated personnel in any reference that contributed in/for the purpose of this research. Further, this research holds no conflict of interest and is not funded through any source.

\section{References}

Adams, D. (1993). Defining educational quality, Improving Educational Quality, Project Publication\# 1: Biennial Report. Arlington, VA: Institute for International Research.

Anderson, S. E. (2000, March). A coordinated district consultant/teacher center centre approach to school-based teacher development: The Mombasa School Improvement Project. In Annual Meeting of the Comparative and International Education Society, San Antonio, Texas.

Brandt, R. S. (2000). Education in a New Era. 2000 ASCD Yearbook. Association for Supervision and Curriculum Development, 1703 N. Beauregard St., Alexandria, VA 22311-1714.

Carron, G., \& Chau, T. N. (1996). The Quality of Primary Schools in Different Development Contexts.

Cazden, C. (2000). In Ensuring Learning Takes Place: A focus on literacy. Human Development Week, World Bank, Washington, DC March.

Colby, J. (2000). Learning outcomes in international context. Paper presented at the Annual Meeting of the Comparative and International Education Society, San Antonio, Texas.

Craig, H. J., Kraft, R. J., \& du Plessis, J. (1998). Teacher Development: Making an Impact. Washington, DC: USAID/ABEL Project \& World Bank. Human Development Network.

Dharmadasa, I. (1996). Parent-Child Literacy Intervention in a Family Development Project in Sri Lanka.

Estrada, M. A. R. (2011). Policy modeling: Definition, classification and evaluation. Journal of Policy Modeling, 33(4), 523-536. https://doi.org/10.1016/j.jpolmod.2011.02.003

Framework, D. (2000). Dakar Framework for Action-Education for All: Meeting Our Collective Commitments. In World Education Forum, UNESCO, Dakar, Senegal held on April (pp. 26-28).

Fuller, B., Dellagnelo, L., Strath, A., Bastos, E. S. B., Maia, M. H., de Matos, K. S. L., \& Vieira, S. L. (1999). How to raise children's early literacy? The influence of family, teacher, and classroom in northeast Brazil. Comparative education review, 43(1), 1-35. https://doi.org/10.1086/447543

Glasser, W. (1990). The quality school: Managing students without coercion. Harper and Row Publishers, Inc., 10 East 53rd Street, New York, NY 10022.

Haddad, W. D., \& Demsky, T. (1995). Education Policy-Planning Process: An Applied Framework. Fundamentals of Educational Planning, 51. UNESCO, 7 Place de Fontenoy, 75700, Paris France.

LeVine, R. (2000). In Ensuring Learning Takes Place: A focus on literacy. Human Development Week, World Bank, Washington, DC March.

McCain, M. N., \& Mustard, F. (1999). Reversing the brain drain: Early study: Final report. Ontario Children's Secretariat, Toronto.

Miske, S. J., \& Dowd, A. J. (1998). Teaching and learning in Mangochi classrooms: Combining quantitative and 
qualitative information to study twelve primary schools in Malawi. Creative Associates International.

Mitchell, D. R. (1995). Special Education Policies and Practices in the Pacific Rim Region.

Obanya, P. (1995). Case studies of curriculum innovations in Western Africa. International Review of Education, 4l(5), 315-336. https://doi.org/10.1007/bf01103032

Postlethwaite, N. (1998). The conditions of primary schools in least-developed countries. International Review of Education, 44(4), 289-317. https://doi.org/10.1023/a:1003213706368

Rutter, M. (1979). Fifteen thousand hours: Secondary schools and their effects on children. Harvard University Press.

Steen, L. A. (1999). Numeracy: The new literacy for a data-drenched society. Educational Leadership, 57, 8-13.

Sutton, M., Tietjen, K., Bah, A., \& Kamano, P. (1999). Promoting Primary Education for Girls in Guinea. CDIE Impact Evaluation.

United Nations Children's Fund. (2000). Curriculum report card. Unicef.

Verwimp, P. (1999). Measuring the quality of education at two levels: A case study of primary schools in rural Ethiopia. International review of education, 45(2), 165-194. https://doi.org/10.1023/a:1003692908335

WHO Expert Committee on Comprehensive School Health Education, \& Promotion. (1997). Promoting Health Through Schools: Report of a WHO Expert Committee on Comprehensive School Health Education and Promotion (No. 870). World Health Organization.

Williams, J. H., \& Cummings, W. K. (2005). Policy-making for education reform in developing countries: Contexts and processes (Vol. 1). R\&L Education.

Willms, J. D. (2002). Standards of care: Investments to improve children's educational outcomes in Latin America. Early Child, 81.

\section{Copyrights}

Copyright for this article is retained by the author(s), with first publication rights granted to the journal.

This is an open-access article distributed under the terms and conditions of the Creative Commons Attribution license (http://creativecommons.org/licenses/by/4.0/). 